\title{
Biomarkers in early colorectal, esophageal, and gastric
} cancer

\author{
Pilar García-Alfonso ${ }^{1}$, Gabriela Torres Pérez-Solero ${ }^{1}$, Javier Soto Alsar ${ }^{1}$, Andrés Muñoz Martin ${ }^{1}$ and Javier Parrondo ${ }^{2}$, \\ ${ }^{1}$ Gastrointestinal Cancer Unit Oncology Departament, Hospital General Universitario Gregorio Marañón, Madrid, Spain. \\ ${ }^{2} \mathrm{~J}$ ParrondoHealth, Coslada Madrid,Spain
}

\begin{abstract}
Gastrointestinal cancer can remain asymptomatic until advanced stages, when treatments tend to be less effective. Therefore, prognosis is poor. Cancer screening programs can help to improve prognosis and patient quality of life through early detection. Biomarkers could prove to be an alternative diagnostic tool and help to select more appropriate treatment. This review focuses on the use of predictive biomarkers in the early diagnosis of colorectal cancer, esophageal cancer, and gastric cancer. Molecular biomarkers based on DNA (methylation of DNA and circulating tumor DNA), RNA, circulating tumor cells, and proteins are being developed for this purpose. These markers have the potential to confirm the diagnosis of the disease in its early stages.
\end{abstract}

\section{Introduction}

The effectiveness of cancer screening has been clearly demonstrated in breast cancer, cervical cancer, and colorectal cancer. We define population screening or early diagnosis as the group of activities applied to nonselected populations with the aim of detecting disease before the first clinical manifestations in order to initiate timely treatment and thus improve prognosis. When this approach is not effective in the general population, it can be restricted to specific population groups, as is the case of hereditary cancer syndromes.

Despite improvements in treatment, gastrointestinal cancer continues to be a major public health problem. Worldwide, colorectal, esophageal cancer, and stomach cancer are among the types of cancer with the highest incidence rates $(10.0 \%, 5.6 \%$, and $3.1 \%$, respectively) and mortality rates $(9.4 \%, 7.7 \%$, and $5.5 \%)[1]$.

Given that these cancers can remain asymptomatic until advanced stages and prognosis is more favorable the sooner the disease is diagnosed, detection at early stages is extremely important if we are to improve prognosis and patient quality of life.

While endoscopic and imaging techniques are the cornerstone of diagnosis in these cancers, the use of biomarkers can help us to improve prognosis by enabling selection of the most appropriate treatment to be chosen and personalized medicine.

Advances in molecular biology show that cancer develops as the simultaneous occurrence of biochemical processes mediated by genetic mutations, microenvironmental factors, and epigenetic abnormalities in such a way that cell clones with selective survival advantages are chosen.

Identification of a biomarker or set of biomarkers can help to develop an alternative diagnostic tool or to select more appropriate treatment.

A predictive biomarker in cancer can be measured objectively (circulating protein, specific circulating cells, or mutated DNA) and used to identify whether a patient has a specific disease (diagnosis), to measure the risk of a person developing the disease, to determine a clinical outcome such as recurrence or death (prognosis), and to predict the response to treatment (prediction).

The ideal predictive marker is reliable, easily available, and detectable using reasonably acceptable laboratory techniques. It is highly specific, is quantitatively associated with tumor volume, and has a very low rate of false positives and a reasonably low rate of false negatives [2].

In recent years, biomarkers have begun to take on an increasingly important role in the detection and treatment of patients with gastrointestinal cancer.

In the case of colorectal cancer, research has been performed to identify molecular markers based on DNA, RNA, and proteins. These will make it possible to develop new, noninvasive detection methods that use biomarkers for screening of colorectal cancer in blood and stool and, hopefully, provide more sensitive and specific tests than those currently available.

Of all cases of colorectal cancer diagnosed, $25 \%$ are characterized by susceptibility to hereditary cancer. Of these, $5 \%$ correspond to hereditary nonpolyposis colorectal cancer (HNPCC) or Lynch syndrome [3] and $1 \%$ to polyposis. Identification of HPNCC has a considerable impact on prevention, since detection of incipient neoplastic lesions can lead to cure rates of $90 \%$ and may affect patients' comorbid conditions and quality of life. In the case of esophageal cancer, numerous markers have been identified based on methylation as a possible biomarker for diagnosis, prognosis, and prediction of the response to treatment [4] Methylation of DNA is an ideal marker for early detection, since

*Correspondence to: Javier Parrondo. JParrondoHealth, Coslada Madrid,Spain. Tel: + 34 910070742. E-mail: jparrondohealth@gmail.com

Key words: colorectal neoplasms; esophageal neoplasms; stomach neoplasms; biomarkers tumor; early detection of cancer

Received: July 06, 2021; Accepted: July 12, 2021; Published: July 19, 2021 
methylation patterns are specific to the type of cancer and appear at early stages of the disease [5].

As for stomach cancer, while various markers have been used for prediction and prognosis, carcinoembryonic antigen (CEA), carbohydrate antigen 19-9 (CA19-9), and cancer antigen 125 (CA125) are the most widely used biomarkers in clinical practice for detection of the disease in the early stages. Circulating tumor cells (CTCs) are a rare and heterogeneous population of cells that circulate in peripheral blood and originate in primary or metastatic tumors. These cells express the antigenic or genetic characteristics of the specific tumor. Diagnosis of gastrointestinal cancers using CTC analysis in liquid biopsy is based on blood, which now replaces tissue biopsy for real-time monitoring of the development of cancer [6-9]. The marked heterogeneity of CTCs has led to the creation of methods aimed at enriching them, isolating them, and/or counting them based on specific molecular or phenotypic characteristics of the different types of cancer.

Analysis of circulating tumor DNA (ctDNA) has helped to refine liquid biopsy by providing an in-depth vision of the heterogeneity of cancer and can be used for early detection [6].

The objective of this article is to review current use and future perspectives of predictive biomarkers in the early diagnosis of colorectal cancer, esophageal cancer, and gastric cancer.

\section{Methods for diagnosis and screening of gastrointestinal cancer}

\section{Colorectal cancer}

Colorectal cancer, together with breast and cervical cancer, is one of the types of cancer for which consensus on the effectiveness of population screening has been reached. Screening is via the fecal occult blood test. Clinical trials analyzing the efficacy of this type of screening show that mortality from colorectal cancer is reduced by $14-15 \%$ in colorectal cancer [10]. However, the sensitivity of the test is limited $(<50 \%)$, and the positive predictive value is low (10-18\% for diagnosis of cancer and $21-38 \%$ for the diagnosis of adenomas greater than 10 $\mathrm{mm})$.

Specificity remains unchanged with the replacement of traditional tests by immunochemistry, and sensitivity is improved, in such a way that fewer false positives are generated, thus reducing the number of confirmatory colonoscopies [11]. The possibility of obtaining better results with screening programs, together with advances in our knowledge of the genetics of cancer, has led to the identification of molecular markers that can be applied in the development of highly accurate noninvasive screening tests.

The various markers investigated for this purpose include DNA [12-14] proteins (e.g., dimeric pyruvate kinase, M2-PK) [15] messenger RNA (mRNA) [16] and micro-RNA (miRNA) [17-19]. However, while they have all demonstrated their potential, only DNA-based markers have undergone the necessary development process and clinical trials for evaluation of their use in clinical practice.

Thus, the stool DNA test was approved by the United States Food and Drug Administration for the population-wide detection of average-risk asymptomatic individuals in 2014.

These tests are based on the fact that colorectal cancer leads to continuous and marked exfoliation of cancer cells from the lumen of the colon, whereas the healthy epithelial cells in the colon are renewed by apoptosis in situ and subsequent phagocytosis by subepithelial macrophages. The fact that bleeding is intermittent and uncommon in adenomas and colorectal cancer could be an advantage over tests that determine occult blood in feces. Detection of DNA after intraluminal lysis of cancer cells is feasible, since these cells have specific epigenetic and genetic abnormalities. In addition, compared with mRNA proteins, DNA is very stable, whereas mRNA is degraded in stool.

While DNA has shown greater sensitivity for detection of advanced adenoma and colorectal cancer than immunohistochemistry testing, it is less specific, with a $10 \%$ frequency of false positives [14]. On the other hand, given its high sensitivity, screening models based on 3-year detection intervals predict very high sensitivity; thus, their rate of false positives is similar to or lower than that of immunohistochemistry. The presence of tumor cells in the bloodstream and other body fluids is a potentially major diagnostic, prognostic, and predictive biomarker. Thus, CTCs in peripheral blood have a negative impact on survival [20]. Detection of CTCs has a series of advantages: extraction is quick and easy; it is inexpensive; and the fact that it is minimally invasive means that pain and risk for patients are reduced. The presence of ctDNA is clinically relevant [13], and miRNA has been reported to play a role in the pathogenesis of colorectal cancer [18]. miRNAs are small noncoding RNAs involved in many cell processes (differentiation, proliferation, and apoptosis).

Consequently, their presence in peripheral blood has been proposed as a major predictive/prognostic biomarker [21]. miRNA from the genes CK19 and CK20 and from CEA in whole blood, plasma, or CTCs has been evaluated in order to find new markers for the detection of colorectal cancer. The overall sensitivity of these markers reached $72 \%$ [22], and their specificity was very high. A large number of miRNA molecules are currently being evaluated as biomarkers, including miR145, miR143, miR135, and miR17-92. Plasma miR29a and miR92a have been shown to have a significant diagnostic value in advanced cancer, with a sensitivity of $83 \%$ and a specificity of $85 \%$ [23].

Protein markers for screening and early detection of colorectal cancer can be divided into tumor antigens, antibodies against tumor antigens, and other relevant proteins. CEA, which was discovered last century, continues to be the only marker with recognized efficacy in the follow-up of patients receiving therapy for colorectal cancer, although its high concentrations are rarely identified in stage 1 disease. Furthermore, since CEA does not differentiate between benign and malignant polyps, we do not recommend it for detection tests [24]. Similar observations can be made for CA19-9, a glycoprotein of controversial diagnostic relevance in colorectal cancer, since it is considered to be less sensitive than CEA. The same is true of other antigens, such as CA195, CA50, and CA72-4, whose diagnostic relevance for colorectal cancer screening is marginal.

Other protein markers evaluated for screening include M2-PK in stool and tissue inhibitor of matrix metalloproteinase 1 (TIMP1). M2$\mathrm{PK}$ is an enzyme involved in energy metabolism that is expressed both in healthy and in cancerous cells. Upregulated expression of M2-PK has been observed in colorectal and other gastrointestinal cancers [25]. Measurement of this enzyme in stool has relatively high sensitivity for colorectal cancer (up to 91\%) and much lower sensitivity for adenomas [26]. Studies also suggest that it is a poorly prognostic fecal or blood marker for screening and/or diagnosis of colorectal cancer [25]. In the case of TIMP1, the plasma level is high in colorectal cancer, although some studies show that it is not significantly higher than that of CEA for cancer screening or suitable for the detection of premalignant lesions [27]. 
Insulin-like growth factor binding protein 2 (IGFBP2) is involved in the proliferation, migration, and invasion of cancer cells; therefore, serum and plasma levels have been used as a diagnostic tool for early detection of colorectal cancer and evaluation of its progression $[28,29]$.

The enzyme telomerase maintains the length of the telomers that protect chromosomes from degrading. Thus, telomerase activity can be used as a diagnostic marker and serves as an independent prognostic factor associated with malignant tumors [30]. While most studies identify telomere shortening as an initial critical event in carcinogenesis, the role of telomere length in cancer cells as a marker in colorectal cancer remains controversial.

Lastly, protein biomarkers include the genes ESM1, CTHRC1, and AZGP1, which have proven effective and significant for diagnosis of colorectal cancer. These genes are secreted in saliva, blood, and urine simultaneously, thus making them candidate biomarkers in colorectal cancer. ESM1 participates in angiogenesis, CTHRC1 can act as a negative regulator in deposition of collagen matrix, and AZGP1 stimulates lipid degradation in adipocytes [31].

With respect to hereditary susceptibility, identification of Lynch syndrome is based on genetic tests aimed at identifying the presence of germline mutations in DNA repair genes (mismatch repair [MMR] genes), such as MLH1, MSH2, MSH6, and PMS2.

Initial screening involves identification of the lack of expression of the proteins corresponding to the genes involved in colorectal cancer or analysis of microsatellite instability (MSI). Either of these techniques is fully accepted today. If an alteration of this type is found, and once the possibility that it is due to an exclusively somatic alteration has been ruled out, germline mutations in MMR genes must be analyzed.

This type of study is being performed in patients with colorectal cancer owing to the preventive implications for the patient and his/ her family and because it helps to select adjuvant therapy when the indication is doubtful [32].

In the case of polyposis syndromes, MSI analysis and/or immunohistochemistry should be performed in all patients diagnosed with colorectal cancer. Germline mutations in MMR genes should continue to be analyzed in patients with MSI and/or loss of expression of repair proteins, providing that an exclusively somatic origin has been ruled out [33]. A summary of the biomarkers of colorectal cancer are shown in Table 1.

\section{Esophageal cancer}

Given the absence of symptoms during the earliest stages of esophageal cancer, presentation and diagnosis are usually late, with a precarious prognosis and very low 5-year survival rates. When the disease is limited to mucosal involvement, early diagnosis is associated with much higher 5-year survival rates (98\%) [34].

Table 1. Biomarkers of colorectal cancer. CTCs: Circulating Tumor Cells; ctDNA: circulating tumor DNA; miRNA: micro RNA

\begin{tabular}{|c|c|}
\hline Detection & Type of test \\
\hline \multirow{3}{*}{ Stool } & Fecal occult blood test \\
\cline { 2 - 2 } & Stool immunochemistry \\
\cline { 2 - 2 } & Stool DNA test \\
\hline \multirow{4}{*}{ Blood } & CTCs \\
\cline { 2 - 2 } & ctDNA \\
\hline & miRNA \\
\hline & Proteins (IGFBP2, ESM1, CTHRC1 and \\
& AZGP1) \\
\hline
\end{tabular}

Table 2. Biomarkers of esophageal cancer. miRNA: micro RNA.

\begin{tabular}{|c|c|}
\hline Detection & Type of test \\
\hline \multirow{2}{*}{ Blood } & miRNA \\
\cline { 2 - 2 } & DNA methylation \\
\hline Exhaled breath & Phenol concentrations \\
\hline
\end{tabular}

The need to make a diagnosis in earlier stages makes biomarkers in blood and exhaled breath the most likely candidates for early detection of esophageal cancer. The development of robust, minimally invasive biomarkers for early detection paves the way for population screening.

The stability and persistence of autoantibodies in serum have made them candidate biomarkers for diagnosis and prognosis of esophageal cancer. Within this group, the tumor suppressor gene and anti-p53 antibodies are absent in healthy plasma but can be detected in the plasma and tissue of patients with various types of cancer, including esophageal cancer [35]. However, their clinical applicability is limited by their low sensitivity, even though their specificity is high. This problem affects many other antibodies.

The diagnostic and prognostic potential of CTCs has been evaluated in esophageal cancer, and their presence has been shown to be correlated with poor overall survival and progression-free survival in Asian populations [36].

Recent studies have evaluated circulating miRNA in plasma/serum as a potential diagnostic and prognostic marker in esophageal cancer. The sensitivity and specificity of circulating miRNA are relatively high $[37,38]$.

DNA methylation is an ideal marker for early detection of cancer, since methylation patterns are cancer-specific, and methylation appears during the initial stages. Aberrant methylation is common in esophageal cancer and contributes to carcinogenesis. Hypermethylation of DNA in tumor suppressor genes has been observed in esophageal cancer, with several possible biomarkers identified for diagnosis of Barret esophagus and esophageal cancer or for predicting the response to treatment and prognosis of esophageal cancer [39]. Consequently, specific methylation markers have identified, and a diagnostic classifier developed [40].

Finally, another noninvasive early detection modality that could prove useful is exhaled breath analysis. This approach can reveal volatile organic compounds, which can act as biomarkers. In this sense, breath alkanes have been associated with cancer as a subproduct of oxidative stress. In the case of esophageal cancer, the exhaled methane concentration has been postulated, although no conclusive results have been reported [41]. A phenol pattern has been identified and appears at higher concentrations in patients with esophageal cancer than in healthy individuals [42]. This observation has led to the development of a predictive model for adenocarcinoma, with a sensitivity of $87.5 \%$ and a specificity of $82.9 \%$ [43]. Given that the model did not reveal significant differences between early-stage and advanced cancer, it could be used for screening.

To date, liquid biopsy of CTCs in esophageal cancer has not been evaluated as a diagnostic marker but has been proposed for evaluation of prognosis and monitoring $[44,45]$. Similar results have been reported for ctDNA [46]. A summary of the biomarkers of esophageal cancer are shown in Table 2.

\section{Stomach cancer}

Identification and treatment in early stages can significantly improve the prognosis of gastric cancer. However, to date, no ideal biomarker has been identified for early screening of gastric cancer. 
Protein biomarkers have also been used as gastric tumor markers in diagnosis, prognosis, and screening of post-treatment recurrence. The many biomarkers that have been used for stomach cancer include alpha-fetoprotein and the antigens CA72-4 and CA12-5. While CEA and CA19-9 are the most widely used in clinical practice, they are used as prognostic markers, since they have not proven successful for diagnosis of early gastric cancer $[47,48]$.

The most commonly used tumor markers for diagnosis of gastric cancer are serum CA72-4, alpha-fetoprotein, and CA125. However, both their specificity and their sensitivity are poor, with the result that none of them is considered for early diagnosis of gastric cancer.

Combined markers have been formulated to increase diagnostic capacity. Proposals include the combination of CEA, CA19-9, and CA72-4 with thymidine kinase 1 (TK1), a biomarker of cell proliferation [49], and the combination of CEA, CA72-4, tumor necrosis factor (TNF), and interleukins 6 and 8 (IL-6 and IL-8) [50], which can significantly increase sensitivity and specificity.

With respect to stomach-specific biomarkers, the combination of the antibodies PGI, PGII, PGI/PGII, G-17, and IgG against Helicobacter pylori has proven able to stratify individuals at high risk of gastric cancer [51], as has the combination of trefoil family factor 3 and pepsinogen [52].

Recent studies have shown that upregulation of the proteins P08493, Q9H939, A0A087WTY6, A0A0G2JMC9, P14207, Q86UD1, and Q8NBP7 and downregulation of P00441, P16157, P62979, and A0A2R8Y7X9 can distinguish between patients with early gastric cancer and healthy individuals [48].

Technical advances in molecular biology in recent years have made it possible to identify oncogenes that can be used as markers for early diagnosis [53]. Overexpression of XPG/ERCC5 [54] and stanniocalcin [55], for example, has been associated with the development and progression of gastric cancer, thus leading them to be proposed as diagnostic and prognostic markers in this disease.

Gastrokine 1 (GKN1) is another possible biomarker. As it protects against gastric cancer, underexpression can be considered an indicator of greater risk of gastric carcinogenesis [56].

The 6 most specific and sensitive methylated genes for gastric cancer are adam 23 , mint 25 , gdnf, prdm5, mlf1, and roar, some of which are more highly methylated than normal in early-stage cancer [57].

As in colorectal cancer and esophageal cancer, specific DNA methylation patterns in gastric cancer have been correlated with tumor size, location, and prognosis, thus making them potential biomarkers of gastric cancer. In the case of gastric tumors, aberrant methylation of DNA is more common than mutations, indicating that DNA methylation is more specific for detection of cancer [57].

With respect to miARN, some are specific to healthy gastric tissue and can act as oncogenes or as suppressors depending on the function of their target gene $[58,59]$. In addition to the specific miRNA that makes it possible to distinguish between patients with gastric cancer, modifications in blood levels of miRNA have been identified in patients affected by the disease [60]. Regulation of miR376c has been reported, even in early-stage gastric cancer, leading to downregulation of the ARID4A gene [61].

Other miRNAs that have been identified for diagnosis and prognosis include miR196a, miR196b, miR501-3p, miR143-3p,
miR451a, miR146a, miR16, miR25, miR92a, miR451, and miR486-5p [62-64].

Long noncoding RNA molecules can also be evaluated for diagnosis of gastric cancer. These are RNA molecules measuring at least 200 nucleotides in length that do not produce proteins involved in processes such as regulation of gene expression. Altered expression of some long noncoding RNAs has been associated with the development of tumors. In addition, these molecules could even act as oncogenes. They are very stable while circulating in body fluids, and their level in tumor tissue is associated with plasma levels; therefore, they can be used for screening of tumors in the early stages [65-67]. The long noncoding RNA PVT1 has proven useful as a biomarker for early detection and prognosis of gastric cancer, since its levels in gastric juice are significantly higher in patients than in healthy individuals [68].

As for selection of plasma biomarkers, levels of HOTAIR [69], ZNFX1-AS1, and HULC are significantly higher in patients with gastric cancer than in healthy controls [70].

Finally, circular RNA (circRNA) are noncoding RNA molecules that form a closed circuit, without 5' or 3' ends [71]. Recent studies have shown aberrant expression of circRNA (circLMTK2, circPSMC3, and circDLST) in tissues affected by gastric cancer compared with healthy adjacent tissue [71,72]. Thus, circRNAs seem promising as biomarkers for diagnosis of gastric cancer, and their expression is specific for cancer and tissues, although they have yet to be analyzed in plasma. Consequently, there is insufficient evidence for their potential as a biomarker of gastric cancer that can be applied in clinical tests and screening [71].

As for liquid biopsy, detection platforms have been developed based on aneuploidy of chromosome 8 , which is recorded in gastric cancer [73]. Nevertheless, the evidence in favor of using detection of CTCs for early detection of gastric cancer is weak. While some data support their usefulness for evaluating the heterogeneity of the tumor, it is necessary to monitor the response to treatment and real-time management of the cancer [74].

In the case of ctDNA, studies have shown that in gastric cancer, its levels are correlated with vascular invasion. The highest detectable levels have been associated with peritoneal recurrence and poor prognosis [75]. A summary of the biomarkers of esophageal cancer are shown in Table 3.

\section{Discusión}

Population screening with the aim of detecting disease before the first clinical manifestations in order to initiate timely treatment and thus improve prognosis has proven effective in breast cancer, cervical cancer, and colorectal cancer. Screening programs are well established in the United States and Europe and have successfully reduced mortality from these cancers thanks to early detection.

Table 3. Biomarkers of stomach cancer. Ab: antibody; miRNA: micro RNA; lncRNA: long noncoding RNA.

\begin{tabular}{|c|c|}
\hline Detection & Type of test \\
\hline \multirow{2}{*}{ Blood } & Ab combination \\
\cline { 2 - 2 } & Protein upregulation and downregulation \\
\cline { 2 - 2 } & DNA methylation \\
\hline Gastric juice & miRNA \\
\hline
\end{tabular}


Unfortunately, to date, no markers have been detected to enable population screening for other types of gastrointestinal cancers, where endoscopy and image-based techniques continue to be the cornerstone of diagnosis.

Molecular biology techniques have enabled the development of markers in the context of advanced cancer, and their use is well established in routine clinical practice. Examples of such markers include BRAF, EGFR, and HER2, which enable us to predict the prognosis of the disease and/or select the most effective drug for its treatment.

The development of new biomarkers to confirm the diagnosis of the disease in its initial stages is expected to improve prognosis.

A good biomarker must meet a series of requirements: it must be reliable, able to be detected using available highly specific laboratory techniques, with a very low false-positive rate and a reasonably low falsenegative rate. Likewise, the techniques should be easy to implement in the primary care setting if their purpose is population screening or in the hospital setting in the case of more restricted screening.

The biomarkers being developed for patients with gastrointestinal cancer are mainly based on proteins, DNA, RNA, cells, and ctDNA (liquid biopsy). While it is true that most are still in the clinical development and validation phases, results reported to date are promising.

The data we report indicate that a combination of biomarkers could improve the early detection of gastrointestinal cancer and evaluation of antitumor therapy. However, given that molecular techniques continue to be too expensive for implementation in health systems, their use for population screening in the short term may be difficult.

The progressive introduction of these techniques and the consequent reduction in their costs should enable them to be implemented in screening programs designed specifically for populations at risk that can later be expanded to population-wide screening programs. Therefore, the effectiveness of a screening strategy depends not only on the performance characteristics of the screening test, but also on uptake in the population. In this sense, it will be important to know the financial constraints that can affect the coverage of screening programs, especially in countries where health care is not free of charge, since a total or partial absence of coverage can lead to inequities in medical care. Thus, approximately one third of Americans eligible for colorectal cancer screening have not been screened [76]. It is estimated that about half of all deaths from colorectal cancer in the United States are due to missed detection opportunities [77].

Regarding screening, cancer detection tests that depend on diagnostic imaging $(\mathrm{Rx})$ carry a risk of additional cancer. Colonoscopy carries a risk of perforation or false positives and is associated with a certain degree of anxiety. These tests often cause significant injury. Thus, the main medical damage of screening occurs in subsequent events such as the diagnostic evaluation of false-positive results or the treatment of cancers that might never have become clinically evident without detection tests (overdiagnosed cases).

In this sense, population screening is justified when the risk of cancer is high enough to justify the risk of overdiagnosis and overtreatment in an otherwise healthy population [78].

A population screening program must have a start and end and a specific periodicity. In low to medium risk populations, the recommended age to start population screening is that at which the risk of cancer begins to increase and when the tumor develops slowly, since slow tumor progression enables identification of a malignancy (or pre-malignancy) at an early stage and thus reduces the incidence of late-stage cancer. This detection is less effective when tumors are fast growing or early spreading, as they tend to occur between detection intervals.

When population screening is not feasible, predictive models can be constructed to help us identify people with a higher risk of cancer than the general population. In these cases, genetic sequencing can detect germline mutations associated with cancer, improve risk stratification, and determine which patients are the best candidates for selective screening programs.

These predictive models will be more successful the greater our knowledge of the determinants of the cancer evaluated. In this sense, research through cohort studies and registries can prove essential in improving screening programs.

\section{Conclusión}

To conclude, while endoscopy and image-based diagnostic techniques continue to be the cornerstone of diagnosis of these diseases, molecular biology techniques have generated biomarkers based on proteins, DNA, RNA, cells, and ctDNA (liquid biopsy). These markers have the potential to confirm the diagnosis of the disease in its early stages, thus improving prognosis.

\section{References}

1. Sung H, Ferlay J, Siegel RL, Laversanne M, Soerjomataram I, et al. (2021) Global cancer statistics 2020: GLOBOCAN estimates of incidence and mortality worldwide for 36 cancers in 185 countries. CA Cancer J Clin 71: 209-249. [Crossref]

2. Italiano A (2011) Prognostic or predictive? It's time to get back to definitions. J Clin Oncol 29: 4718. [Crossref]

3. Wells K, Wise PE (2017) Hereditary colorectal cancer syndromes. Surg Clin North Am 97: 605-625.

4. Hao X, Luo H, Krawczyk M, Wei W, Wang W, et al. (2017) DNA methylation markers for diagnosis and prognosis of common cancers. Proc Natl Acad Sci U S A 114: 74147419. [Crossref]

5. Koch A, Joosten SC, Feng Z, de Ruijter TC, Draht MX, et al. (2018) Analysis of DNA methylation in cancer: location revisited. Nat Rev Clin Oncol 15: 459-466. [Crossref]

6. Alix-Panabières C, Pantel K (2016) Clinical applications of circulating tumor cells and circulating tumor dna as liquid biopsy. Cancer Discov 6: 479-491. [Crossref]

7. Cheng F, Su L, Qian C (2016) Circulating tumor DNA: A promising biomarker in the liquid biopsy of cancer. Oncotarget 7: 48832-48841. [Crossref]

8. Heitzer E, Haque IS, Roberts CES, Speicher MR (2019) Current and future perspectives of liquid biopsies in genomics-driven oncology. Nat Rev Genet 20: 71-88.

9. Pantel K, Alix-Panabières C (2017) Liquid biopsy in 2016: Circulating tumour cells and cell-free DNA in gastrointestinal cancer. Nat Rev Gastroenterol Hepatol 14: 73-74. [Crossref]

10. Heresbach D, Manfredi S, D'Halluin PN, Bretagne JF, Branger B (2006) Review in depth and meta-analysis of controlled trials on colorectal cancer screening by faecal occult blood test. Eur J Gastroenterol Hepatol 18: 427-433. [Crossref]

11. Bretagne JF, Piette C, Cosson M, Durand G, Lièvre A (2019) Switching from guaiac to immunochemical faecal occult blood test increases participation and diagnostic yield of colorectal cancer screening. Dig Liver Dis 51: 1461-1469. [Crossref]

12. Shah R, Jones E, Vidart V, Kuppen PJ, Conti JA, et al. (2014) Biomarkers for early detection of colorectal cancer and polyps: systematic review. Cancer Epidemiol Biomarkers Prev 23: 1712-1728. [Crossref]

13. Ma Z, Williams M, Cheng YY, Leung WK (2019) Roles of methylated DNA biomarkers in patients with colorectal cancer. Dis Markers 2019: 2673543. [Crossref]

14. Imperiale TF, Ransohoff DF, Itzkowitz SH, Levin TR, Lavin P, et al. (2014) Multitarget stool DNA testing for colorectal-cancer screening. NEngl J Med 370: 1287-1297. [Crossref] 
15. Shastri YM, Loitsch S, Hoepffner N, Povse N, Hanisch E, et al. (2008) Comparison of an established simple office-based immunological FOBT with fecal tumor pyruvate kinase type M2 (M2-PK) for colorectal cancer screening: Prospective multicenter study. Am J Gastroenterol 103: 1496-1504. [Crossref]

16. Takai T, Kanaoka S, Yoshida K, Hamaya Y, Ikuma M, et al. (2009) Fecal cyclooxygenase 2 plus matrix metalloproteinase $7 \mathrm{mRNA}$ assays as a marker for colorectal cancer screening. Cancer Epidemiol Biomarkers Prev 18: 1888-1893. [Crossref]

17. Fadaka AO, Pretorius A, Klein A (2019) Biomarkers for stratification in colorectal cancer: MicroRNAs. Cancer Control 26: 1073274819862784. [Crossref]

18. Shirafkan N, Mansoori B, Mohammadi A, Shomali N, Ghasbi M, et al. (2018) MicroRNAs as novel biomarkers for colorectal cancer: New outlooks. Biomed Pharmacother 97: 1319-1330. [Crossref]

19. Slaby O (2016) Non-coding RNAs as biomarkers for colorectal cancer screening and early detection. Adv Exp Med Biol 937: 153-170. [Crossref]

20. Tan CR, Zhou L, El-Deiry WS (2016) Circulating tumor cells versus circulating tumor DNA in colorectal cancer: pros and cons. Curr Colorectal Cancer Rep 12: 151-161. [Crossref]

21. Herreros-Villanueva M, Duran-Sanchon S, Martín AC, Pérez-Palacios R, Vila-Navarro E, et al. (2019) Plasma MicroRNA signature validation for early detection of colorectal cancer. Clin Transl Gastroenterol 10: e00003. [Crossref]

22. Shen C, Hu L, Xia L, Li Y (2008) Quantitative real-time RT-PCR detection for survivin, CK20 and CEA in peripheral blood of colorectal cancer patients. Jpn J Clin Oncol 38 : 770-776. [Crossref]

23. Huang Z, Huang D, Ni S, Peng Z, Sheng W, et al. (2010) Plasma microRNAs are promising novel biomarkers for early detection of colorectal cancer. Int J Cancer 127 : 118-126. [Crossref]

24. Duffy MJ, Lamerz R, Haglund C, Nicolini A, Kalousová M, et al. (2014) Tumor markers in colorectal cancer, gastric cancer and gastrointestinal stromal cancers: European group on tumor markers 2014 guidelines update. Int J Cancer 134: 2513 2522. [Crossref]

25. Kapoor S (2013) Pyruvate kinase M2 and its evolving role as a prognostic marker in systemic malignancies besides colorectal carcinomas. Tumor Biology 34: 611.

26. Mulder SA, van Leerdam ME, van Vuuren AJ, Francke J, van Toorenenbergen AW, et al. (2007) Tumor pyruvate kinase isoenzyme type M2 and immunochemical fecal occult blood test: Performance in screening for colorectal cancer. Eur J Gastroenterol Hepatol 19: 878-882. [Crossref]

27. Nielsen HJ, Brünner N, Jorgensen LN, Olsen J, Rahr HB, et al. (2011) Plasma TIMP1 and CEA in detection of primary colorectal cancer: a prospective, populationbased study of 4509 high-risk individuals. Scand J Gastroenterol 46: 60-69. [Crossref]

28. Ladd JJ, Busald T, Johnson MM, Zhang Q, Pitteri SJ, et al. (2012) Increased plasma levels of the APC-interacting protein MAPRE1, LRG1, and IGFBP2 preceding a diagnosis of colorectal cancer in women. Cancer Prev Res (Phila) 5: 655-664. [Crossref]

29. Liou J-M, Shun C-T, Liang J-T, Chiu H-M, Chen M-J, Chen CC, et al. (2010) Plasma insulin-like growth factor-binding protein-2 levels as diagnostic and prognostic biomarker of colorectal cancer. J Clin Endocrinol Metab 95: 1717-1725. [Crossref]

30. Fernández-Marcelo T, Sánchez-Pernaute A, Pascua I, De Juan C, Head J, et al. (2016) Clinical relevance of telomere status and telomerase activity in colorectal cancer. PLOS ONE 11: e0149626. [Crossref]

31. Ding D, Han S, Zhang H, He Y, Li Y (2019) Predictive biomarkers of colorectal cancer. Comput Biol Chem 83: 107106.

32. Sepulveda AR, Hamilton SR, Allegra CJ, Grody W, Cushman-Vokoun AM, et al. (2017) Molecular biomarkers for the evaluation of colorectal cancer: guideline from the American society for clinical pathology, college of American pathologists, association for molecular pathology, and the American society of clinical oncology. J Clin Oncol 35: 1453-1486. [Crossref]

33. García-Alfonso P, García-Carbonero R, García-Foncillas J, Pérez-Segura P, Salazar R, et al. (2020) Update of the recommendations for the determination of biomarkers in colorectal carcinoma: National consensus of the spanish society of medical oncology and the spanish society of pathology. Clin Transl Oncol 22: 1976-1991. [Crossref]

34. Jankowski JHB, Fau WK, Delaney B (2010) Diagnosis and management of Barrett's oesophagus. BMJ 341: c4551. [Crossref]

35. Zhang J, Xv Z, Wu X, Li K (2012) Potential diagnostic value of serum $\mathrm{p} 53$ antibody for detecting esophageal cancer: a meta-analysis. PLoS One 7: e52896. [Crossref]
36. Zhang Y, Deng H, Chen G, Tang Z, Mao J, et al. (2020) Clinicopathological and prognostic value of circulating tumor cells in esophageal carcinoma: A meta-analysis. Ann Palliat Med 9: 4271-4282. [Crossref]

37. Hou X, Wen J, Ren Z, Zhang G (2017) Non-coding RNAs: New biomarkers and therapeutic targets for esophageal cancer. Oncotarget 8: 43571-43578. [Crossref]

38. Niu C, Zhao L, Guo X, Shen Y, Shao Y, et al. (2019) Diagnostic accuracy of circRNAs in esophageal cancer: A meta-analysis. Dis Markers 2019: 9673129. [Crossref]

39. Ma K, Cao B, Guo M (2016) The detective, prognostic, and predictive value of DNA methylation in human esophageal squamous cell carcinoma. Clin Epigenetics 8: 43. [Crossref]

40. Li D, Zhang L, Liu Y, Sun H, Onwuka JU, et al. (2019) Specific DNA methylation markers in the diagnosis and prognosis of esophageal cancer. Aging (Albany NY) 11: 11640-11658. [Crossref]

41. Abela JE, Skeldon KD, Stuart RC, Padgett MJ (2009) Exhaled ethane concentration in patients with cancer of the upper gastrointestinal tract - a proof of concept study. Biosci Trends 3: 110-114. [Crossref]

42. Kumar S, Huang J, Abbassi-Ghadi N, Španěl P, Smith D, et al. (2013) Selected ion flow tube mass spectrometry analysis of exhaled breath for volatile organic compound profiling of esophago-gastric cancer. Anal Chem 85: 6121-6128. [Crossref]

43. Kumar S, Huang J, Abbassi-Ghadi N, Mackenzie HA, Veselkov KA, et al. (2015) Mass Spectrometric Analysis of Exhaled Breath for the Identification of Volatile Organic Compound Biomarkers in Esophageal and Gastric Adenocarcinoma. Ann Surg 262 981-990. [Crossref]

44. Hoeppner J, Kulemann B (2017) Circulating tumor cells in esophageal cancer. Oncol Res Treat 40: 417-422.

45. Onidani K, Shoji H, Kakizaki T, Yoshimoto S, Okaya S, et al. (2019) Monitoring of cancer patients via next-generation sequencing of patient-derived circulating tumor cells and tumor DNA. Cancer Sci 110: 2590-2599. [Crossref]

46. Kato S, Okamura R, Baumgartner JM, Patel H, Leichman L, et al. (2018) Analysis of circulating tumor dna and clinical correlates in patients with esophageal, gastroesophageal junction, and gastric adenocarcinoma. Clin Cancer Res 24: 62486256. [Crossref]

47. Feng F, Tian Y, Xu G, Liu Z, Liu S, et al. (2017) Diagnostic and prognostic value of CEA, CA19-9, AFP and CA125 for early gastric cancer. BMC Cancer 17: 737. [Crossref]

48. Zhou B, Zhou Z, Chen Y, Deng H, Cai Y, et al. (2020) Plasma proteomics-based identification of novel biomarkers in early gastric cancer. Clin Biochem 76: 5-10. [Crossref]

49. Ning S, Wei W, Li J, Hou B, Zhong J, Xie Y, et al. (2018) Clinical significance and diagnostic capacity of serum TK1, CEA, CA 19-9 and CA 72-4 levels in gastric and colorectal cancer patients. $J$ Cancer 9: 494-501. [Crossref]

50. Li J, Xu L, Run ZC, Feng W, Liu W, et al. (2018) Multiple cytokine profiling in serum for early detection of gastric cancer. World J Gastroenterol 24: 2269-2278. [Crossref]

51. Tu H, Sun L, Dong X, Gong Y, Xu Q, et al. (2017) A serological biopsy using five stomach-specific circulating biomarkers for gastric cancer risk assessment: A multiphase study. Am J Gastroenterol 112: 704-715. [Crossref]

52. Lee HS, Jeon SW, Nomura S, Seto Y, Kwon YH, et al. (2018) Screening biomarker as an alternative to endoscopy for the detection of early gastric cancer: The combination of serum trefoil factor family 3 and pepsinogen. Gastroenterol Res Pract 2018: 1024074. [Crossref]

53. Necula L, Matei L, Dragu D, Neagu AI, Mambet C, et al. (2019) Recent advances in gastric cancer early diagnosis. World J Gastroenterol 25: 2029-2044. [Crossref]

54. Deng N, Liu JW, Sun LP, Xu Q, Duan ZP, et al. (2014) Expression of XPG protein in the development, progression and prognosis of gastric cancer. PLoS One 9: e108704. [Crossref]

55. Fang Z, Tian Z, Luo K, Song H, Yi J (2014) Clinical significance of stanniocalcin expression in tissue and serum of gastric cancer patients. Chin J Cancer Res 26: 602610. [Crossref]

56. Altieri F, Di Stadio CS, Federico A, Miselli G, De Palma M, et al. (2017) Epigenetic alterations of gastrokine 1 gene expression in gastric cancer. Oncotarget 8: 1689916911. [Crossref]

57. Ebrahimi V, Soleimanian A, Ebrahimi T, Azargun R, Yazdani P, et al. (2020) Epigenetic modifications in gastric cancer: Focus on DNA methylation. Gene 742: 144577. [Crossref] 
58. Naeli P, Pourhanifeh MH, Karimzadeh MR, Shabaninejad Z, Movahedpour A, et al. (2020) Circular RNAs and gastrointestinal cancers: Epigenetic regulators with a prognostic and therapeutic role. Crit Rev Oncol Hematol 145: 102854. [Crossref]

59. Zhou Y, Huang T, Siu HL, Wong CC, Dong Y, et al. (2017) IGF2BP3 functions as a potential oncogene and is a crucial target of miR-34a in gastric carcinogenesis. Mol Cancer 16: 77. [Crossref]

60. Link A, Kupcinskas J (2018) MicroRNAs as non-invasive diagnostic biomarkers for gastric cancer: Current insights and future perspectives. World J Gastroenterol 24: 3313-3329. [Crossref]

61. Hung PS, Chen CY, Chen WT, Kuo CY, Fang WL, et al. (2017) miR-376c promotes carcinogenesis and serves as a plasma marker for gastric carcinoma. PLoS One 12 e0177346. [Crossref]

62. Jiang X, Wang W, Yang Y, Du L, Yang X, et al. (2017) Identification of circulating microRNA signatures as potential noninvasive biomarkers for prediction and prognosis of lymph node metastasis in gastric cancer. Oncotarget 8: 65132-65142. [Crossref]

63. Tsai MM, Wang CS, Tsai CY, Huang CG, Lee KF, et al. (2016) Circulating microRNA$196 \mathrm{a} / \mathrm{b}$ are novel biomarkers associated with metastatic gastric cancer. Eur J Cancer 64: $137-148$.

64. Wang J, Zhang H, Zhou X, Wang T, Zhang J, Zhu W, et al. (2018) Five serumbased miRNAs were identified as potential diagnostic biomarkers in gastric cardia adenocarcinoma. Cancer Biomark 23: 193-203. [Crossref]

65. Bhan A, Soleimani M, Mandal SS (2017) Long noncoding RNA and cancer: A new paradigm. Cancer Res 77: 3965-3981. [Crossref]

66. Hong SH, Kwon JT, Kim J, Jeong J, Kim J, et al. (2018) Profiling of testis-specific long noncoding RNAs in mice. BMC Genomics 19: 539.

67. Sanchez Calle A, Kawamura Y, Yamamoto Y, Takeshita F, Ochiya T (2018) Emerging roles of long non-coding RNA in cancer. Cancer Sci 109: 2093-2100. [Crossref]

68. Yuan CL, Li H, Zhu L, Liu Z, Zhou J, Shu Y (2016) Aberrant expression of long noncoding RNA PVT1 and its diagnostic and prognostic significance in patients with gastric cancer. Neoplasma 63: 442-429. [Crossref]
69. Elsayed ET, Salem PE, Darwish AM, Fayed HM (2018) Plasma long non-coding RNA HOTAIR as a potential biomarker for gastric cancer. Int J Biol Markers 2018: 1724600818760244. [Crossref]

70. Xian HP, Zhuo ZL, Sun YJ, Liang B, Zhao XT (2018) Circulating long non-coding RNAs HULC and ZNFX1-AS1 are potential biomarkers in patients with gastric cancer. Oncol Lett 16: 4689-4698. [Crossref]

71. Jiang F, Hong F, Shah MW, Shen X (2019) Circular RNAs as diagnostic biomarkers in gastric cancer: A meta-analysis review. Pathol Res Pract 215: 152419. [Crossref]

72. Yu CY, Kuo HC (2019) The emerging roles and functions of circular RNAs and their generation. J Biomed Sci 26: 29.

73. Li Y, Zhang X, Ge S, Gao J, Gong J, et al. Clinical significance of phenotyping and karyotyping of circulating tumor cells in patients with advanced gastric cancer. Oncotarget 5: 6594-602. [Crossref]

74. Uchôa Guimarães CT, Ferreira Martins NN, Cristina da Silva Oliveira K, Almeida CM, Pinheiro TM, et al. (2018) Liquid biopsy provides new insights into gastric cancer. Oncotarget 9: 15144-15156. [Crossref]

75. Fang WL, Lan YT, Huang KH, Liu CA, Hung YP, et al. (2016) Clinical significance of circulating plasma DNA in gastric cancer. Int J Cancer 138: 2974-2983. [Crossref]

76. White A TT, White MC, Sabatino AS, Moor JD, Rose DVP, et al. (2017) Cancer screening test use - United States, 2015. MMWR Morb Mortal Wkly Rep 66: 201-206. [Crossref]

77. Meester RG, Doubeni CA, Lansdorp-Vogelaar I, Goede SL, Levin TR, et al. (2015) Colorectal cancer deaths attributable to nonuse of screening in the United States. Ann Epidemiol 25: 208-213.e1. [Crossref]

78. Esserman LJ, Thompson IM, Reid B, Nelson P, Ransohoff DF, et al. (2014) Addressing overdiagnosis and overtreatment in cancer: a prescription for change. Lancet Oncol 15 e234-42. [Crossref]

Copyright: (C2021 García-Alfonso P. This is an open-access article distributed under the terms of the Creative Commons Attribution License, which permits unrestricted use, distribution, and reproduction in any medium, provided the original author and source are credited. 